\author{
가동중원전의 일반규격품 품질검증 이행 체계 구축 방안 \\ 염동운 ${ }^{\dagger}$ 장희승 · 송태영 \\ 한국수력원자력(주) \\ (2014년 3월 26일 접수, 2014년 6월 9일 수정, 2014년 6월 11일 채택)
}

\title{
An Establishment of Commercial Grade Item Dedication Implementing System for Operating NPPs in Korea
}

\author{
Dong Un Yeom ${ }^{\dagger} \cdot$ Hee Seung Chang · Tae Young Song \\ Korea Hydro \& Nuclear Power Co.
}

(Received 26 March 2014, Revised 9 June 2014, Accepted 11 June 2014)

요약

\begin{abstract}
국내 가동중원전은 2012년 이후 일반규격품 품질검증 이행 체계 구축을 위해 정책 수립 및 기술 개발, 일반규격품 품질검증 전문기관 양성, 국내 원전 공급사들의 일반규격품 품질검증프로그램 보유 추진 및 원자력 산업계의 전문인력 양성 등을 적극 추진 중에 있다. 아울러 미국 전력연구소(EPRI)의 관련 기술기준을 기반으로 일반규격품 품질검증프로그램 도입 초기에 개발된 안전성(Q) 등급 품목 품질검증 프로세스를 개선하였고, 국내 원전 고유의 원자력 품질등급 체계인 안전성영향(A) 등급 품목 을 위해 안전성등급 품목과 차별화시킨 별도의 검증 프로세스를 개발하였다.

결과적으로, 위와 같은 노력을 통해 국내 가동중원전의 일반규격품 품질검증 이행 체계가 구축될 경우, 원전에서 사용하는 기자재의 신뢰성 및 안전성이 향상될 것으로 기대된다.
\end{abstract}

주요어 : 일반규격품 품질검증, 안전성(Q) 등급, 안전성영향(A) 등급

\begin{abstract}
A Commercial Grade Item Dedication(CGID) for Korean operating nuclear power plants has been implemented since 2012. The CGID implementation and strategies for Korea are established as follows: CGID policy establishment, R\&D of a specific methodologies of CGID, enrollment of third party organizations for CGID work, CGID program establishment for enrolled suppliers, establishment of training courses for certification, and CGID process development for quality class Q and A.

Consequently, it is expected that these activities are enable to enhance the reliability and the safety of components and/or parts in nuclear power plants.
\end{abstract}

Key words : Commercial grade item dedication(CGID), Quality Class Q or A

\section{1. 서 론}

국내 가동중원전은 대내·외 원자력 산업계의 변화 에 따라 원전에서 사용할 안전성관련 품목을 납품하

\footnotetext{
${ }^{\dagger}$ To whom corresponding should be addressed.

Korea Hydro \& Nuclear Power Company, Central Research Institute 25-1, Jang-dong, Yuseong-gu, Daejeon, Korea Tel : 042-870-5633 E-mail : www@khnp.co.kr
}

던 공급사들이 더 이상 원자력 품질보증프로그램을 보유하지 않거나, 납품하던 제품을 생산 중단함에 따 라 국내 원전에서 정비 시에 사용할 기자재를 적기에 확보할 수 없는 경우를 대비하여, 2002년도에 미국으 로부터 일반규격품 품질검증(CGID, Commercial Grade Item Dedication) 프로그램을 도입하였다.

일반적으로 CGID란 일반산업규격(KS, ISO 등)으 로 생산된 품목을 원자력 품질보증프로그램 하에서 
제작된 안전성관련 품목 대신 사용하기 위해 전문가 의 기술평가와 적합성 확인과정을 통해 합리적으로 검증하는 것을 말한다.

아울러 원전에서는 특수성 및 안전성을 고려 일반 산업계에서 널리 적용하는 품질보증프로그램(KS, ISO 등) 대신 원자력의 특수성에 맞춰 품질요건을 보 다 강화시킨 원자력 품질보증프로그램을 운영하고 있 으며, 국내 가동중원전에서는 안전성 $(\mathrm{Q})$, 안전성영향 (A) 및 일반산업 $(\mathrm{S})$ 등급 등 3 가지의 품질등급 체계 를 운영하고 있다.

국내에 CGID 프로그램 도입 초기, 가동중원전은 미국 전력연구소(EPRI, Electric Power Research Institute)에서 개발한 기술기준을 기반으로 일반규격 품을 안전성등급 품목으로 사용하기 위한 일반규격품 품질검증 프로세스를 개발하였으며, 미국 원전과 품 질등급 체계가 상이한 안전성영향등급 품목에 대해서 는 별도의 프로세스 개발 없이 안전성등급 프로세스 를 유사한 수준으로 확대 적용하였다.

아울러 국내 가동중원전은 CGID 프로그램 도입 후 지난 10 년간 원전에서 사용할 기자재의 신뢰성 향 상을 위해, CGID 이행 기술 및 경험이 풍부한 해외 공급사 및 일반규격품 품질검증 전문기관을 주로 활 용하면서 국내 일반규격품 품질검증 체계 구축에는 다소 미흡하였다.

하지만 2012년 말에 발생한 국내 원전 일부 공급 사들의 일반규격품 품질검증서류 위조사건은 국내 원 전의 CGID 이행 실태를 재점검해 보는 계기가 되었 고, 유사사례 재발방지를 위해 국내 가동중원전의 일 반규격품 품질검증 이행 체계 구축 필요성이 대두되 었다.

따라서 본 논문에서는 2012년 말의 일반규격품 품 질검증서류 위조사건 이후 국내 가동중원전에서 지속 적으로 추진하고 있는 일반규격품 품질검증 이행 체 계 구축 방안에 대해 고찰해 보고자 한다.
2. 일반규격품 품질검증 개요

미국의 TMI 2호기 원전 사고 이후 원자력 산업계 의 전반적인 침체에 따라 미국에서는 원전 안전성관 련 품목 제작사들이 보유하고 있던 원자력 품질보증 프로그램(10CFR50 App. B)을 포기하거나, 제작사 도산 또는 제품 업그레이드 등으로 안전성관련 품목 을 생산중단하게 되었다. 이에 따라 공급사들이 원전 에 위조 품목을 납품하거나, 원전에서 안전성관련 품 목 대신 일반규격품을 사용하는 등의 품질위반사례가 증가하게 되었다.

그 결과, 원전에서 사용할 기자재의 품질확보를 위 한 대체 프로그램 개발의 필요성이 대두되어 미국 전 력연구소(EPRI)에서 관련 기술기준들을 개발하였다 [1 3]. 또한, 미국 규제기관(NRC)에서는 법령 $10 \mathrm{CFR} 21$ 개정 및 규제지침을 발표하여 미국 내 원 자력사업자들이 일반규격품 품질검증(CGID)을 수행 할 수 있게 하였다[4,5]. 이후 대부분의 미국 및 캐나 다 원전에서는 기자재 구매의 효율성 및 경제성을 고 려 적극적으로 CGID 프로그램을 활용하고 있다.

따라서 경수로형 및 중수로형 원전 도입으로 안전 성관련 기자재 구입 시 해외 의존성이 높아 선진국의 환경 변화에 크게 영향을 받는 국내 원전에서도 2002 년도에 미국으로부터 CGID 프로그램을 도입하게 되 었으며, 국내 규제기관에서도 관련 규제지침을 개발 하였다[6].

CGID란 Fig. 1에서 보는 바와 같이 산업체에서 생 산한 일반규격품에 대한 기술평가 및 적합성 확인 후 안전성관련 품목으로 사용할 수 있는 지를 검증하는 것을 말한다. 즉, 안전성관련 품목이 구매 중단 또는 단종될 경우 안전기능을 수행하는 원전 구조물, 계통 또는 기기에 사용할 일반규격품이 원자력 품질보증프 로그램(10CFR50 App. B) 하에서 설계 및 제작된 안 전성관련 품목과 동등한 수준임을 합리적으로 보증하 고, 설계 시 제시된 안전기능 수행이 가능함을 입증

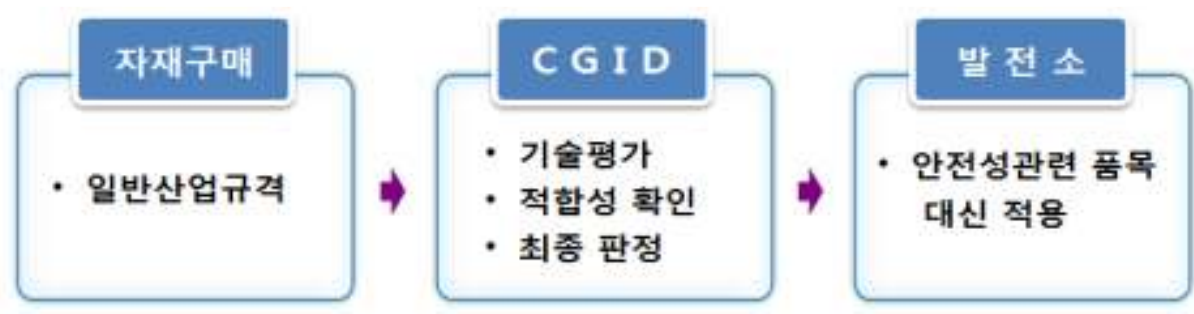

Fig. 1. CGID Implementing Process 
하는 활동이다.

일반규격품 구매 후 해당 품목에 대한 기술평가 단 계에서는 대상품목 식별, 모기기 및 품목의 안전기능 분석 후 필수특성을 도출하며, 적합성 확인 단계에서 는 특수시험 및 검사, 일반규격품 공급자 실사, 제작 중 입회검사, 공급사 및 품목 이력 평가 등의 방법을 통해 각각의 필수특성 별로 적합성을 확인한다.

최종 판정 단계에서는 필수특성별 판정기준에 부 합하는 지 평가한 후 일반규격품을 안전성관련 품목 으로 사용할 수 있는 지 확인하는 단계이며, 만족할 경우 해당 품목을 안전성관련 품목 대신 발전소에 적 용하게 된다.

\section{3. 국내 가동중원전의 CGID 이행 체계 구축}

2012년까지 국내 가동중원전에서는 대내·외 공신 력 확보를 위해 미국 원전사업자구매협의체(NUPIC, Nuclear Procurement Issues Committee)로부터 인증 받은 해외 일반규격품 품질검증 전문기관을 활용하여 CGID를 수행하였으며, 국내 CGID 이행 기반은 미 미하였다.

이에 따라 국내 가동중원전의 일반규격품 품질검 증 이행 체계 구축을 위해 정책수립 및 기술개발, 국 내 일반규격품 품질검증 전문기관 양성, 공급사들의 CGID 프로그램 보유 추진 및 원자력 산업계 품질검 증 인력 양성 등 4 가지 방안을 추진하게 되었으며, 세부적인 내용은 다음과 같다.

\section{3-1. CGID 이행 정책수립 및 기술개발}

국내 가동중원전에서 일반규격품 품질검증(CGID) 을 체계적으로 이행하기 위해 내부 정책을 수립하고, 관련 기술개발을 Table 1 과 같이 추진 중에 있다. 우
선적으로 CGID 이행 범위를 명확히 결정하였고, CGID 수행 주체를 구분하였다.

아울러 미국 전력연구소(EPRI)의 CGID 분야 전문 가 초청 기술세미나를 통해 미국 및 캐나다 원전의 CGID 이행 기술 및 경험을 입수하여 정책에 반영하 였으며, 안전성등급과 차별화 시킨 안전성영향등급 검증 프로세스를 개발하였다. 향후에는 부적합사항 처리 지침, CGID 품목별 비용 적정단가 산정기준, 일반규격품 품질검증 관리시스템 및 품목별 필수특성 적용기준 개발을 통해 국내 가동중원전의 CGID 이 행 체계를 확고히 할 예정이다.

\section{3-2. 일반규격품 품질검증 전문기관 양성}

국내에 CGID 프로그램 도입 후 2012년까지 가동 중원전에서는 공급사로 등록된 다수의 해외 일반규격 품 품질검증 전문기관을 활용하여 $\mathrm{CGID}$ 를 이행하였 고, 국내에서는 한수원 중앙연구원에서 자체적으로 일부 품목에 대한 CGID를 수행하였다. 이후 국내 CGID 이행 기반 강화 및 신속한 기자재 조달을 위해 한수원 중앙연구원에 전담조직을 신설하고, 인력을 확충하여 시급성을 요구하는 품목들에 대한 검증을 수행하고 있다.

대외적으로는 Table 2와 같이 국내 일반규격품 품 질검증 전문기관 양성에 착수하여 기술분야 심사기준 개발, 공급사 등록신청 공고, 공공 시험기관 대상 등 록설명회 개최, 안전성등급 시험기관 및 품질검증 전 문기관 등록을 추진하였다. 아울러 국내 품질검증 전 문기관 양성을 위해 지속적으로 희망기관을 대상으로 기술지원을 추진 중에 있다.

\section{3-3. 원전 공급사 CGID 프로그램 보유 추진}

미국 및 캐나다에서는 일반규격품 품질검증 전문

Table 1. Policy Establishment and R\&D of CGID Implementation

\begin{tabular}{|c|c|c|c|}
\hline 번호 & 추 진 항 목 & 일 정 & 비 고 \\
\hline 1 & 가동중원전의 CGID 이행 방안 수립 & '13.04 & \\
\hline 2 & 미 전력연구소(EPRI) 전문가 기술세미나 개최 & '13.07 & \\
\hline 3 & 가동중원전의 CGID 이행 범위 결정 및 공급사 전파 & '13.08 & \\
\hline 4 & 안전성등급 CGID 이행 프로세스 개선 & '13.10 & \\
\hline 5 & 안전성영향등급 검증 프로세스 개발 & ' 13.10 & \\
\hline 6 & CGID 부적합사항 처리 지침 개발 & '14.08 & \\
\hline 7 & CGID 품목별 비용 적정단가 산정 지침 개발 & '14.08 & \\
\hline 8 & 일반규격품 품질검증 관리시스템 개발 & '14.09 이후 & \\
\hline 9 & CGID 품목별 필수특성 적용기준 개발 & '14.09 이후 & \\
\hline
\end{tabular}


Table 2. Table Policy Establishment and R\&D of CGID Implementation

\begin{tabular}{c|c|c|c}
\hline 번호 & \multicolumn{1}{|c}{ 추 진 항 목 } & 일 정 & 비 고 \\
\hline \hline 1 & 일반규격품 품질검증기관 등록평가 심사기준 개발 & '13.02 & \\
\hline 2 & 일반규격품 품질검증기관 등록신청 공고 & $' 13.02$ & \\
\hline 3 & KOLAS 인증 공공 시험기관 대상 설명회 개최 & $' 13.05$ & \\
\hline 4 & 안전성등급 CGID 시험기관 등록 (3개 기관) & $' 13.06$ & \\
\hline 5 & 한전KPS(주) 품질검증 전문기관 등록 & '14.02 & \\
\hline 6 & 일반규격품 품질검증 전문기관 양성 지속 지원 & - & \\
\hline
\end{tabular}

Table 3. Activities for establishing CGID Program of Suppliers

\begin{tabular}{c|c|c|c}
\hline 번호 & \multicolumn{1}{|c}{ 추 진 항 목 } & 일 정 & 비 고 \\
\hline \hline 1 & 국내 안전성등급 공급사 대상 CGID 설명회 개최 & '13.05 & \\
\hline 2 & 표준 일반규격품 품질검증 이행 지침 개발 & '13.07 & 공급사 제공 \\
\hline 3 & CGID 프로그램 구축 안내서 개발 & '13.07 & 공급사 제공 \\
\hline 4 & 안전성 및 안전성영향등급 공급사 대상 설명회 개최 & '13.12 & \\
\hline 5 & 국내 공급사 대상 CGID 기술교류회 개최 & '13.12 & \\
\hline 6 & 공급사 CGID 프로그램 보유 독려 및 기술지원 & - & \\
\hline
\end{tabular}

Table 4. Activities for managing CGID Education Course

\begin{tabular}{c|l|l|l}
\hline 번호 & \multicolumn{1}{|c|}{ 추 진 항 목 } & 일 정 & 비 고 \\
\hline \hline 1 & 대한전기협회 일반규격품 품질검증 교육과정 개설 & '13.02 & \\
\hline 2 & $\begin{array}{c}\text { 대한전기협회(KEPIC) 주관 CGID 교육과정 운영 } \\
\text { '13년 3회 수행 (총 36개사, 110명 교육 이수) }\end{array}$ & '13.04 09 & \\
\hline 3 & '14년도 교육과정 2회(상·하반기) 운영 예정 & - & \\
\hline
\end{tabular}

기관 뿐만 아니라 원전에 안전성관련 품목을 납품하 는 공급사들도 자체적으로 CGID를 수행하고 있으며, 자체 시험설비를 보유하고 있지 않은 일부 소규모 공 급사들의 경우에는 경제성을 고려 일반규격품 품질검 증 전문기관을 활용하여 $\mathrm{CGID}$ 를 이행하고 있다. 즉, 공급사들의 경우 자체 설계한 품목 조립 시 소요되는 일반규격 부속부품에 대한 설계특성 및 기능을 가장 정확하게 파악하고 있으므로 실질적으로 공급사가 납 품품목에 들어가는 일반규격 부속부품에 대한 CGID 를 수행하는 것이 최적의 방법이다.

이에 따라 Table 3 과 같이 국내 공급사들의 CGID 프로그램 보유를 위해 국내 원전에 공식 등록된 50 여 개의 안전성등급 공급사들을 대상으로 1 차 설명회를 개최하였고, 표준 일반규격품 품질검증 이행 지침 및 안내서를 개발하여 제공함으로써 공급사들의 CGID 프로그램 보유 추진을 용이하게 하였다. 또한, 안전성 (Q) 및 안전성영향(A) 등급 70여개의 공급사들을 대 상으로 2 차 설명회 및 기술교류회를 개최하여 최신 정보 및 경험교류를 추진하였으며, 기자재 납품 시의 편의성 제고를 위해 지속적으로 CGID 프로그램을 보유토록 독려 및 기술지원하고 있다.
3-4. 일반규격품 품질검증 전문인력 양성

2012년 말에 발생한 국내 원전의 일반규격품 품질 검증서류 위조사건 전까지 국내 원자력 산업계의 $\mathrm{CGID}$ 에 대한 인식은 거의 미미한 수준이었으며, 원 자력 사업자의 자체 교육과정을 제외하고는 국내 산 업계 및 교육기관에서 일반규격품 품질검증 교육과정 을 운영하는 곳은 전무하였다.

이에 따라 국내 가동중원전의 CGID 이행 체계 구 축을 위해서는 원자력 산업계의 일반규격품 품질검증 전문인력 양성이 가장 시급하여 Table 4와 같이 대한 전기협회(KEPIC, Korea Electric Power Industry Code)와 협의 후 일반규격품 품질검증 교육과정 개 설 및 전문인력 양성을 추진하였으며, 2013년도에 36 개사 110 명이 교육을 이수하였고, 2014년도에는 상. 하반기(2회) 교육과정을 운영할 계획이다. 아울러 향 후에도 일반규격품 품질검증 전문기관 및 공급사들의 품질검증 전문인력 양성을 위해 지속적으로 강사지원 등 해당 교육과정 운영을 기술지원 할 예정이다.

4. 일반규격품을 안전성 $(\mathrm{Q})$ 등급 품목으로 검증 방안 
대부분의 미국 원전은 원자력 품질등급 체계를 Safety(안전성)와 Non-safety(비안전성) 2가지로 운영 하고 있으며, CGID 프로그램은 Safety(안전성) 관련 품목에 대해서만 적용하고 있다.

국내 가동중원전의 품질등급 체계는 미국 원전과 상이하게 안전성(Q), 안전성영향(A) 및 일반산업(S) 등급 등 3 가지로 구분하여 운영하며, CGID 프로그램 적용 시 안전성등급 품목에 대해서는 대내·외 신뢰성 확보를 위해 미국 원전과 동일한 방법론을 적용하고 있다.

반면에 안전성영향등급 품목에 대해서는 미국 원 전과 달리 품질보증활동을 수행해야 하는 국내 가동 중원전의 고유특성을 감안하여 안전성등급 CGID 프 로그램과 차별화시킨 별도의 검증 프로그램을 개발하 여 적용하고 있다.

따라서 2012년 이후 국내 가동중원전에서 개선 후 적용 중인 일반규격품을 안전성등급 품목으로 검증하 는 프로세스의 특성 및 방안은 다음과 같다.

\section{4-1. 안전성등급 품목 검증 특성}

가동중원전에서 안전성등급 품목 관련 CGID는 국 내 원전에 등록된 해당 품목(부품)의 안전성등급 공 급사가 없는 경우, 해당 품목의 단종 또는 설계서류 에 일반규격품을 사용토록 명시된 3 가지의 경우에 한 하여 수행할 수 있다.

안전성등급 품목 CGID 수행 주체는 사업자 자체 수행, 국내·외 원전 공급사 또는 일반규격품 품질검 증 전문기관 수행 등으로 구분하며, Fig. 2는 사업자 자체 수행 및 공급사에서 수행하는 품질검증 흐름을 보여주고 있다. 단, 공급사가 $\mathrm{CGID}$ 를 수행할 경우에
는 가동중원전에 등록된 품목 제작 시 소요되는 일반 규격 부속부품(안전기능 수행)으로 그 대상을 엄격하 게 제한하고 있다.

만일에 가동중원전에 설치될 품목(A'ssy)이 일반산 업(S) 등급 기능을 수행한다면, 품목(A'ssy) 제작 시 소요되는 일반규격 부속부품은 CGID 이행 대상이 아니다. 또한, 품목(Ass'y) 제작 시 소요되는 일반규 격 부속부품이 안전성등급 기능을 수행하나, 원자력 품질보증프로그램에 의해 다음의 5 가지 요건을 만족 하도록 체계적으로 관리된다면 CGID를 수행하지 않 는다. 단, 체계적인 관리가 되지 않아 일반규격 부속 부품의 신뢰성을 확보 할 수 없을 경우에는 CGID를 수행하여야 한다.

하지만 품목(A'ssy) 제작 시 소요되는 일반규격 부 속부품(안전성등급 기능 수행)만을 예비품으로 별도 로 납품할 경우에는 $\mathrm{CGID}$ 를 수행하여야 한다.

· 공급사의 품목(Ass'y)이 원전에 안전성등급 품목 으로 등록

- 공급사의 원자력 품질보증계획서 또는 절차서에 일반규격품 관리요건 반영

· 공급사의 부속부품(일반규격품) 납품업체 목록 관리

- 부속부품(일반규격품)의 설계특성(규격, 기능, 동 작 등) 문서화

. 일반규격 부속부품 시험 및 완성품(Ass'y) 성능시 험 수행

공급사 또는 일반규격품 품질검증 전문기관은 품 질향상을 위해 CGID 수행 전에 일반규격품 품질검 증계획(CGID Plan)을 발주자인 사업자에게 제출 후

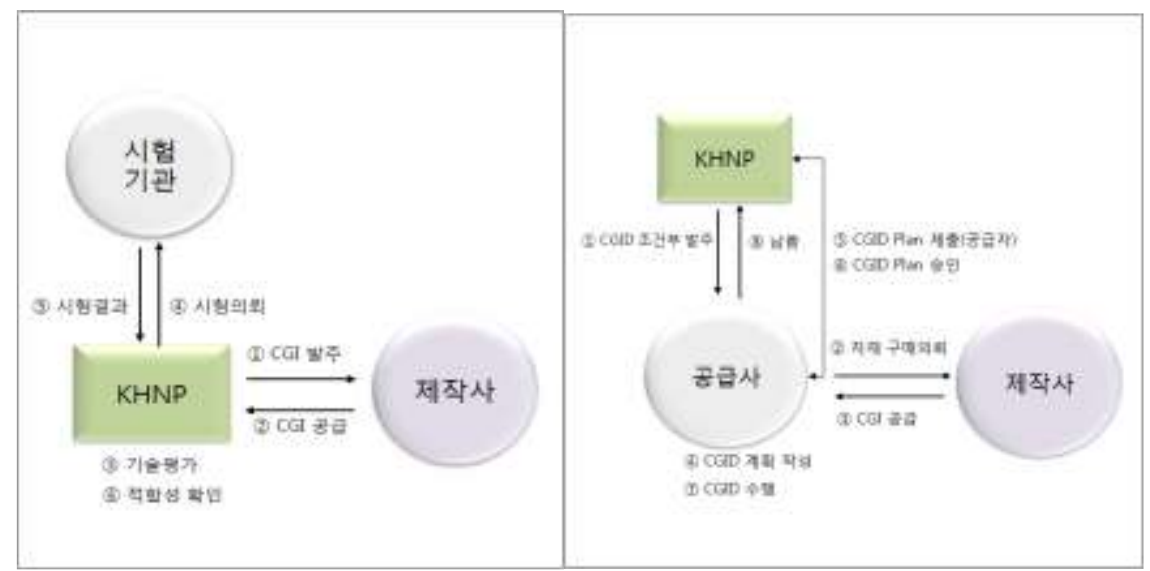

Fig. 2. Flow of CGID Implementation 
승인받아야 하며, 일반규격품 품질검증보고서(CGID Report)는 납품 시에 제출하여야 한다. 이때 CGID Plan은 사업자인 발주자인 한수원 중앙연구원의 전문 가들이 검토 후 승인한다.

일반규격품 품질검증계획(CGID Plan) 및 일반규 격품 품질검증보고서(CGID Report)를 제출할 수 없 는 경우에는 사전 협의 후 아래 방법들 중 한 가지 이상을 적용하여 품질을 확보해야 한다.

- 발주자의 현장입회를 통한 CGID 시험/검사 또는 서류 확인

· 최근 3 년 이내 규제기관, 원전사업자협의체 (NUPIC, CANPAC 등) 또는 발주자의 CGID 관 련 감사실적 제출

· 최근 5년 이내 일반규격품 품질검증 품목 납품 실 적 제출

\section{4-2. 안전성등급 품목 검증 방법}

Fig. 3 에서 보는 바와 같이 일반규격품에 대한 기 술평가 및 적합성 확인 후 안전성등급 품목으로 사용 할 수 있는 지를 검증한다. Fig. 3 에서 일반규격품 구 매 후 해당 품목에 대한 기술평가 단계에서는 대상품 목 식별, 모기기 및 품목의 안전기능 분석 후 필수특 성을 도출한다.

대상품목 식별이란 교체 대상 품목의 예비품 확보 여부, 대체품 적용의 필요성 및 기존 품목과의 규격 및 기능을 비교하는 것이며, 안전기능 분석이란 원전 의 설계문서, 인·허가 서류, 계통도면 및 기술규격서 등을 검토하여 해당 품목이 수행해야 할 안전기능을 검토하는 것이다. 필수특성 선정은 기술평가의 핵심 단계이며, 해당 품목의 식별요건, 물리적 특성 및 성 능특성 등을 분석하여 일반규격품으로 구매된 품목이

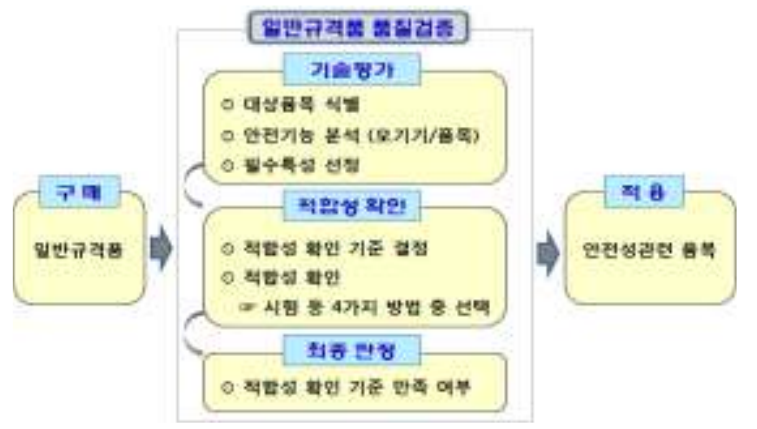

Fig. 3. CGID Implementing Process
설계상 안전기능을 수행하기 위해 입증해야 할 정성 적, 정량적 평가기준을 수립하는 것이다.

적합성 확인 방법에는 특수시험 및 검사, 일반규격 품 공급자 실사, 제작 중 입회검사, 공급사 및 품목의 이력 평가 등 4 가지가 있으며, 이 가운데서 한 가지 방법을 적용하거나 한 가지 이상을 조합하여 수행한 다. 일반적으로는 특수시험 및 검사 방법을 가장 많 이 사용하고 있다.

특수시험 및 검사는 퓨즈, 커패시터 및 차단기 등 과 같이 단순하며 설계·제작-시험 등이 표준화된 품 목, 표준화 또는 자동화된 검사-시험 방법으로 필수 특성을 확인할 수 있는 품목들에 대해 적용한다. 일 반규격품 공급사 실사는 공급사에 대한 현장실사를 통해 해당 품목의 필수특성에 대한 품질보증 이행 실 태를 확인하는 방법이며, 복잡한 품목을 대상으로 사 용한다. 제작 중 입회검사는 복잡한 품목을 대상으로 대상 품목의 설계, 제작, 시험 및 선적 출하 등 입회 를 통해서만 필수특성을 확인할 수 있는 경우, 공급 사의 품질활동이 필수특성을 확인하는데 적합하지 않 다고 판단되는 경우에 적용한다. 공급자 및 품목 이 력평가는 일정기간 또는 일정량의 품목을 대상으로 공급사의 공급실적과 발전소 운전 이력을 평가하여 만족여부를 판정한다.

최종 판정 단계에서는 적합성 확인 결과가 필수특 성별 판정기준에 부합하는 지 평가한 후 일반규격품 을 안전성관련 품목으로 사용할 수 있는 지를 최종 확인한다. 그 결과, 만족할 경우에는 안전성관련 품목 대신 사용할 수 있다.

5. 일반규격품을 안전성영향(A) 등급 품목으로 검증 방안

\section{5-1. 안전성영향등급 품목 검증 특성}

국내 가동중원전에서 일반규격품의 안전성영향 등 급 검증 $(\mathrm{CGID} \mathrm{A)}$ 은 사업자 자체 수행, 일반규격품 품질검증 전문기관 또는 안전성영향등급 이상의 원전 등록 공급사가 수행할 수 있다. 단, 공급사의 검증 범 위는 안전성등급과 동일하게 원전에 등록된 공급사 품목의 부속부품으로 한정한다.

일반산업(S) 등급 기능을 수행하는 품목(A'ssy) 제 작 시 소요되는 일반규격 부속부품(일반규격품)은 CGID A 대상이 아니다. 또한, 품목(Ass'y) 제작 시 소요되는 일반규격 부속부품이 안전성영향등급 기능 


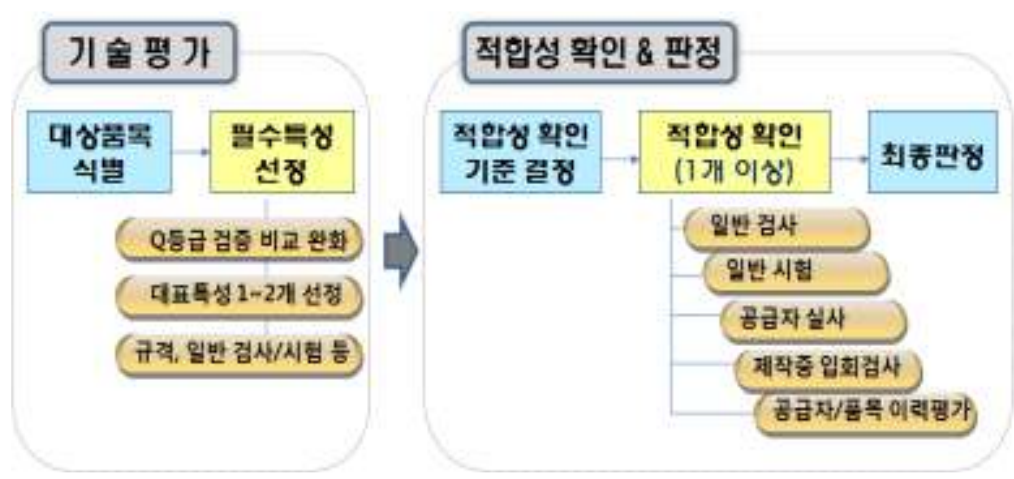

Fig. 4. CGID A Implementing Process

을 수행하나, 원자력 품질보증프로그램에 의해 다음 과 같이 3 가지의 요건을 만족하도록 체계적으로 관리 된다면 CGID A를 수행하지 않는다.

하지만 품목(A'ssy) 제작 시 소요되는 일반규격 부 속부품(A등급 기능 수행)만을 예비품으로 별도로 구 매 할 경우에는 반드시 CGID A를 수행하여야 한다.

- 공급사의 품목(Ass'y)이 원전에 안전성영향등급 이상의 품목으로 등록

· 공급사의 부속부품(일반규격품) 납품업체 목록 관 리

- 일반규격 부속부품 시험 또는 완성품(Ass'y) 조립 후 성능시험 수행

일반규격품을 안전성영향등급으로 검증할 경우 안 전성등급과 달리 일반규격품 품질검증계획(CGID A Plan)을 작성하지 않으며, 품질검증보고서(CGID A Report)는 납품 시 제출한다. 해외 공급사들에게 CGID A를 의뢰할 경우에는 해외 원전과 국내 가동 중원전과의 원자력 품질등급 체계가 상이한 점을 고 려하여 구매 시 Dedication을 요구하거나 신뢰성을 확보할 수 있는 주요 시험 또는 검사요건을 제시하여 야 한다[7].

\section{5-2. 안전성영향등급 품목 검증 방법}

Fig. 4에서 일반규격품을 안전성영향등급으로 사용 하기 위해 검증하는 방법은 안전성등급 프로세스를 준용하여 개발하였고, 기술평가 및 적합성 확인은 안 전성등급 품목 검증과의 차별화를 위해 이행 절차를 간소화 및 완화시켰으며, 주요 검증내용은 다음과 같 다.
필수특성 선정은 해당 품목의 물리적 또는 성능특 성을 대표하는 것으로 1 2가지 종류만 선정할 수 있 다. 규제요건, 발전정지유발기기 또는 비상운전 절차 와 관련이 없는 품목의 경우에는 필수특성 선정 시 해당 품목의 규격, 일반적인 검사 또는 보편적인 시 험 등 간단한 특성을 적용할 수 있다.

필수특성 검증을 위한 적합성 확인 시에는 주요 검 사, 주요 시험, 일반규격품 공급사 실사, 제작 중 입 회검사 또는 공급사 품목 이력평가 중에서 한 가지 이상의 방법을 활용하며, CGID A 수행 시 해당 품목 의 수량이 많을 경우에는 기술기준에서 제시한 표본 검사를 수행할 수 있다.

\section{6. 결 론}

일본의 후쿠시마 원전 사고 이후 전 세계적으로 원 자력 산업이 위축되는 분위기 속에서, 원자력 품질보 증프로그램 보유를 포기하는 공급사들이 증가할 것으 로 예상된다. 이 경우, 국내 가동중원전에서도 정비 시 소요되는 기자재의 적기 공급이 중요한 현안이 될 수 있으며, 이때 안전성 $(\mathrm{Q})$ 또는 안전성영향(A) 등급 기자재를 적기에 확보하기 위한 가장 효과적인 대응 방안은 CGID 프로그램을 활용하는 것이다.

이에 따라 국내 가동중원전에서도 2012년 이후 CGID 정책수립 및 기술개발, 일반규격품 품질검증 전문기관 양성, 국내 공급사 CGID 프로그램 보유 추 진 및 일반규격품 품질검증 전문인력 양성 등 일반규 격품 품질검증 이행 체계 구축을 적극적으로 추진 중 에 있다.

또한, 미국 전력연구소(EPRI)의 기술기준을 기반 으로 기 개발된 안전성 $(\mathrm{Q})$ 등급 품질검증 프로세스를 전문가 초청 기술세미나 및 국내 원전의 CGID 이행 
경험 등을 반영하여 개선하였고, 국내 원전 고유의 품질등급 특성인 안전성영향(A) 등급 품목에 대해서 는 안전성등급 프로세스와 차별화시킨 별도의 프로세 스를 개발하였다.

이와 같은 노력은 원전에서 사용할 기자재의 신뢰 도 제고 및 원전의 안전성 향상을 위한 필연적인 과 정이며, 원자력 사업자, 공급사 및 관련기관 모두 국 내 원전의 안정적인 운영을 위해서는 일반규격품 품 질검증 이행 체계 구축을 위해 상호 협조 및 노력을 기울여야 할 것이다.

\section{References}

1. Electric Power Research Institute (EPRI), "Guideline for the Utilization of Commercial Grade Items in Nuclear Safety Related Applications (NP-5652)", June 1988, 1-117

2. Electric Power Research Institute (EPRI), "Guideline for the Technical Evaluation of Replacement Items in Nuclear Power Plants (NP-6406)", December 1989, 1-123

3. Electric Power Research Institute (EPRI), "Supplemental Guidance for the Application of EPRI Report NP-5652 on the Utilization of Commercial Grade Items (TR-102260)", March 1994, 1-143

4. US Nuclear Regulatory Commission (NRC), "Reporting of Defects and Noncompliance (10CFR21)", 369-376

5. US Nuclear Regulatory Commission (NRC), "License Commercial Grade Procurement and Dedication Programs (GL 91-05)", April, 1991, 5-7

6. 한국원자력안전기술원 (KINS), "안전성관련품 목 대체사용을 위한 일반규격품의 품질검증 (KINS/RG-N17.12)" 2005, 1-7

7. 김정운, 염동운, 장희승, "일반규격품의 안전성 영향등급 사용을 위한 검증 방안", 한국압력기 기공학회, 2013.11, 1-2 